\title{
Online surface roughness characterization of paper and paperboard using a line of light triangulation technique
}

\author{
Anzar Alam, Anatoliy Manuilskiy, Jan Thim, Mattias O'Nils, Johan Lindgren and Joar Lidén
}

\begin{abstract}
KEYWORDS: Paper, paperboard, Newspaper, Online surface measurement, OnTop, Line of light triangulation, Paper smoothness, Paper roughness, Optical measurement, laser application.
\end{abstract}

SUMMARY: Within both the paper and paperboard industries, real time monitoring and measurement of surface roughness of a paper moving at high velocities is an important and challenging area of research. The uniform surface, for an entire production, can be effectively achieved by monitoring and controlling the paper surface roughness, in real time during the manufacturing steps. Presently the majority of paper industries rely on traditional laboratory profilometers. The obvious limitations of lab profilometers are that these are slow, do not measure the quality of entire reels but rather deal with only a few small pieces of samples taken from the end of the reels and it is difficult to make any possible correction in the production lines without knowing the online roughness data. To eradicate the disadvantages associated with conventional measurements, an online prototype instrument has been developed that measures the surface roughness during the manufacturing steps, and is based on a line of light triangulation technique. The prototype technique will be of assistance in ensuring tight process control in order to maintain both a better and a uniform quality throughout the entire production. It measures the whole reel, meter by meter, in traditional units of roughness and is also capable of characterizing the topography in a wide range of wavelength spectra. The article presents the online analyses results obtained from the developed prototype. The real time measurements, in a paperboard pilot mill, have successfully characterized and distinguished 16 different grades of newspaper and paperboard reels including reels which have the same family of quality grades and materials.

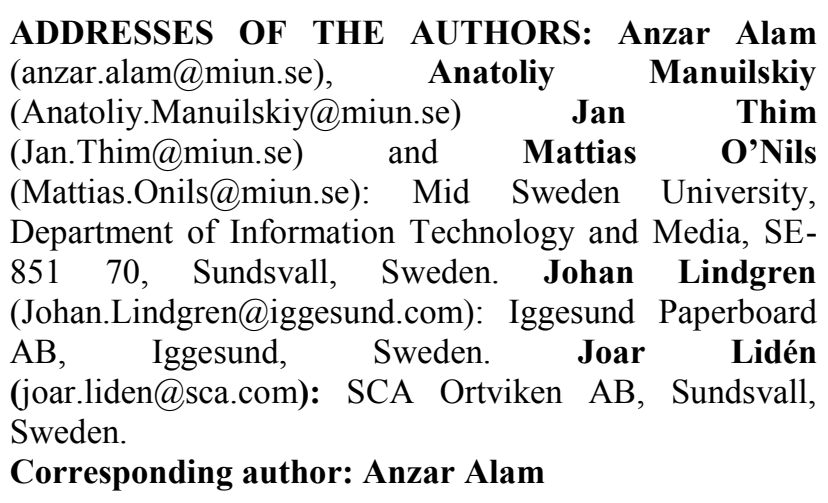

Topography is the field of study which deals with the outof-plane properties of a surface including a wide range of geometrical irregularities and in which roughness is one of the components of the topography. The roughness of a paper or paperboard surface is recognized as being one of the most important paper properties, in relation to the printability, coating and consumption of inks (Pino et al. 2010; Aguilar et al. 2009; Schwaiger et al. 2009; Vernhes at el. 2008; Ma 2005; Costa et al. 2005). For example, the value of a graphical paper product is mainly dependent on the perceived surface quality (Goic et al. 2011; Thim et al. 2009). Roughness relates to paper properties including gloss, uneven grammage distribution and friction (Pierre at el. 2008; Gunnar and Veronique 1994). Papers are often coated and the amount of coating depends upon the surface quality of the base paper/paperboard and it is also true that the amount of coating is influenced by the requirements of the final paper/board product. Paper process researchers have been endeavoring to improve the processing techniques in order to enhance the quality of the manufactured paper and this is the reason why many processing steps, for example, calendering, coating, and hot calendering are in fact undertaken mainly to improve the surface smoothness (Samyn et al. 2011; Litvinov and Farnood 2006; Rättö 2005; Hansson and Johansson 1999). The surface property is one of the critical parameters used for either the acceptance or rejection of the final product (Tay and Quan 2003).

Because the importance of the surface quality of the manufactured paper and paperboard, a number of hi-tech industrial laboratory profilometers are available, including both contact and non-contact techniques. Among the contact techniques, air leak methods have been in use over the years in both the paper and paperboard industries as they are considered to be very reliable. There are various air leak measurement methods, including Bekk, Bendtsen and Parker Print Surf (PPS) which are widely used. There is a common basic working principle for all of the air leak instruments which is that a rough paper sample will act as a poor seal in relation to the pressurized air and will allow a high rate of air flow through its surface, while a smooth surface will act as a good seal and will restrict the rate of air flow through its surface. Air leak roughness is measured by the rate of air flow in $\mathrm{ml} / \mathrm{min}$. The mechanical stylus is also a contact based technique and this consists of a fine preloaded diamond tip which is mechanically dragged over the surface under test. The stylus tip traverses the surface irregularities in order to measure the topography along a line. The vertical resolution of the stylus depends upon the diameter of the tip which can be approximately a few $\mu \mathrm{m}$ (Ostadi 2010). The mechanical stylus is used for hard surfaces such as metals. In both the case of the air leak and stylus, destructive tests are conducted and thus measurements are non repeatable.

The Atomic Force Microscope (AFM) measures the soft surfaces including paper without any damage as its tip is very fine and has a very high vertical resolution in the nanometer range. 
However, there are obvious limitations in laboratory measurements. For example, the absence of real time surface quality data while paper was being manufactured and a few laboratory samples, usually taken from the end of the paper reels, cannot represent the entire reel as measurements have not been taken across the whole length. Furthermore, not only would there be large local variations over the length of the reel, but rolling force and speeds are reduced at the beginning and end of the reel, thus yielding changes in properties at the sampling position as compared to those for the remainder of the reel (Bilstein et al. 2007). The surface dynamic properties, which develop during the manufacturing process such as cockling and long waviness, will not appear with the same intensity on the lab samples. Therefore, the conventional laboratory measurement is not sufficient and there has thus been a requirement for online surface measurements.

There has long been a request for measurements relating to the whole length of a reel in order to ensure and improve the quality of all paper and paperboard products. Online surface measurements, directly on the machines, will be of great use. The real-time surface topography, including roughness, cockling, waviness and dynamic variations are of prime importance in order to investigate and fix the problems.

The conventional methods, as discussed above, for example, air leak is good in relation to a laboratory situation but is not valid for online measurements and the mechanical contact stylus has a poor resolution and conducts a destructive test and thus it is not possible to apply these methods to online paper testing. AFM and other high resolution microscopes are sophisticated and have been designed for laboratory conditions. It is thus the case that non-contact optical techniques offer a strong potential for online measurements.

The real time monitoring and measurement of surface roughness, on a paper web, is an important and challenging research area (Pino et al. 2010; Kuparinen et al. 2005). Paper web at high velocities introduces some additional features to the surface due to vibrations, stress on surface, and noise etc. During online measurements these features also become part of the actual surface topography, making it difficult to measure the true surface roughness (Schwaiger et al. 2009). The speed of the paper machine can reach $2000 \mathrm{~m} / \mathrm{min}$ or higher and thus an online technique must be capable of taking measurements across a wide range of operating speeds. The resolution of the online device should be sufficiently high in order to distinguish between individual wood fibers.

The optical techniques, used in laboratory instruments, are for example interferometric, laser triangulation, laser scanning profilometry (Hladnik and Lazar 2011) and confocal microscopy, which enables measurements of a surface with precision (Goic et al. 2011). Researchers are focusing on non-contact optical based measurement techniques. For example, Hansson and Johansson in 2000 developed a photometric stereo technique, which was implemented by Åslund in 2004 to make a fast surface measurement setup (Åslund et al. 2004). Barros and Johansson, designed a laboratory profilometer, the
'Optitopo' in 2005, to measure paper surface roughness which was also based on the photometric stereo principle (Barros, Johansson 2005).

The online optical roughness assessment is an emerging research area and new measuring techniques are being explored (Wu et al. 2008). In the majority of techniques, the target surface is illuminated either by a pulse source or by a continuous light source. The reflected light from the surface is captured by a CCD camera(s). The physical region of the paper surface illuminated by the light source can be a point, a line or an area.

There are a few online devices available which are designed to detect mainly a surface fault as this is also important (Rodríguez-Jiménez et al. 2010). There are also some devices which measure surface roughness within a short range of wavelengths and thus there was a requirement for an online device that can comprehensively measure and analyze the surface topography within a wide range of wavelength.

A new prototype, the Online Topography (OnTop) device, based on a pulsed line of light triangulation technique, has recently been developed. The triangulation is a proven technique, well known, simple and is low cost designed (Cheng et al. 2007). The prototype, OnTop, has been tested at the Pilot Coating Plant at Iggesund Paperboard Mill in Sweden. It is designed to measure the paper and paperboard web surfaces meter by meter for an entire reel during the manufacturing process. It measures, a $210 \mathrm{~mm}$ long web-width, and estimates surface height irregularities in traditional units of average roughness Ra, root mean square roughness $\mathrm{Rq}$, and is also capable of characterizing surface topography in a wide range of wavelength spectral regions (Alam et al. 2012).

The online measurement in the production line, will reduce the requirements for frequent physical inspections (Wu et al. 2008) and provide an opportunity to perform timely corrective actions so as to maintain the desired quality of the finished products. It will assist in reducing wastages and will enhance the quality in an efficient manner.

The intention of this study is to present the performance and accuracy of the OnTop device. The correlation results between the online measurement made by OnTop and those made by the industrial laboratory profilometer are shown. The online characterization results, on the basis of rms roughness $\mathrm{Rq}$, are presented for the sample reels consist of both wide and narrow topographical differences and include samples of the same family material and grades.

\section{Materials and Methods}

The online surface roughness measurements were taken and analyzed, in this study, by means of the developed prototype in the Pilot Coating Machine of Iggesund Paperboard Mill, Iggesund Sweden.

\section{OnTop prototype}

The developed prototype is based on technique involving a non-contact line of light triangulation. According to ASME B46.1-2002 standards the prototype lies in the category of 'Type II Full Profiling non-contact 
instruments' which includes the measurement techniques generally based on optical and electronics sensors.

Since it was previously concluded by Alam et al. (2011) that for paper and paperboard the roughness levels are in general higher in the cross direction (CD) than in the machine direction (MD), the prototype is designed to scan a line of light in the CD. An installation picture and a sketch are shown in Fig 1 which indicates the exact location of the OnTop and the measurement in the CD. The aim of this study was mainly to measure the surface roughness and thus the location chosen in the trial tests was quite stable and suitable for measuring the roughness. However, different locations can also be chosen depending upon the interest of topographical components.

The majority of the laboratory optical profilometers scan a sample point by point (Ren et al. 2010) in order to create a vector of a line profile. Since the prototype is designed on a line of light projection technique, a vector of a line-profile is obtained in a single step which makes a rapid acquisition of the entire line. A robust prototype assembly with a fast algorithm was built as these are among the criteria for online production devices (Rodríguez-Jiménez et al. 2010).

The prototype consists of two semiconductor pulsed laser sources of $900 \mathrm{~nm}$ wavelength having an operating energy of about 150 pjoules, two plano-convex cylindrical lenses of $40 \mathrm{~mm}$ focal length, the option of selecting 1 to 3 CCD sensors, a trigger pulsed generator, a timing control unit and DC power sources. A beam of laser source is transformed into a sharp thin line using cylindrical lenses and projected onto the surface of the paper web. The low-specular reflected line of light from the paper surface, which carries the surface topographical information, is captured by cameras. The captured images are processed by image processing techniques which include, the fast acquisition of images synchronized with the pulsed laser sources, pre-processing and postprocessing filters, cropping the region of interest, a line profile processing algorithm and the transformation from a time domain to a frequency domain. Finally, the averages of multiple measurements and quantitative results in the form of $\mathrm{Ra}$ and $\mathrm{Rq}$ are obtained.

The accuracy of the overall system can deteriorate due to the noise in the electronic system, the imaging sensor, and speckle in the laser line. The average noise based on $\mathrm{Rq}$ was found to be $8.1 \mathrm{~nm}(4.3 \%)$, calculated when the long-wavelength cutoff $\lambda \mathrm{c}$ was $8.75 \mathrm{~mm}$. The imaging sensor resolution in the horizontal axis was 1600 pixels and, as each sensor captures a $70 \mathrm{~mm}$ physical length (evaluation length) on the paper surface, the spatial resolution is $43.75 \mu \mathrm{m}$.

\section{Sample reels descriptions}

There were 8 sample reels in total including 4 newspapers and 4 paperboards, since each reel was measured separately on two sides, a total of 16 surfaces measured. For example reels 1 and 2 are physically the same reel, but when its topside was measured, it was numbered as Reel 1 and when the wireside was measured, it was numbered as Reel 2. Similarly, the

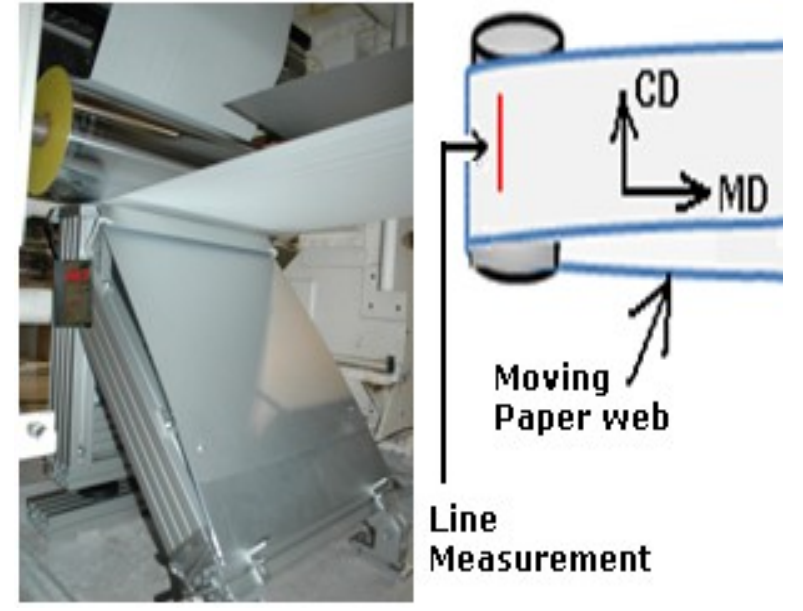

Fig 1. Indicates the exact location of the OnTop in the figure at the left. The two figures show the location of the measurement on the moving paper web along cross direction.

paperboard reels were also measured separately for the uncoated and coated sides and numbered accordingly. These 16 surfaces were examined online and listed in Table 1. The samples consist of different grades and weights of newspaper and paperboard reels. The paperboard samples consist of the edge and the middle reels. The edge reels are those which were taken from the edge position of the master reel and the middle reels were taken from the middle positions of the master reel. It is commonly known that the difference in surface quality between the edge and middle positions is very small but it is also known that the level of roughness, in general, is higher at the edge positions than at the middle position, due to shrinkages during the manufacturing process. The edge and middle reels were deliberately included in the study in order to measure the roughness of almost similar surfaces where the differences are very low. These reels played important roles in order to evaluate the accuracy and performance of the prototype. The paperboard reels were provided by Iggesund Paperboard AB, Iggesund, Sweden and the Newspaper reels by SCA Ortviken Paper Mill, Sundsvall, Sweden.

Table I. Sample reels description.

\begin{tabular}{lll}
\hline $\begin{array}{l}\text { Reel } \\
\text { Nr. }\end{array}$ & Description & Surface \\
\hline 1 & 43 gsm Newspaper & Topside \\
2 & 43 gsm Newspaper & Wireside \\
3 & 49 gsm Newspaper & Topside \\
4 & 49 gsm Newspaper & Wireside \\
5 & 51 gsm Newspaper & Topside \\
6 & 51 gsm Newspaper & Wireside \\
7 & 60 gsm Newspaper & Topside \\
8 & 60 gsm Newspaper & Wireside \\
9 & Edge-position paperboard & Uncoated \\
10 & 20 gsm Edge-position paperboard & Coated \\
11 & Middle-position paperboard & Uncoated \\
12 & 20 gsm middle-position paperboard & Coated \\
13 & Edge-position paperboard & Uncoated \\
14 & 24 gsm Edge-position paperboard & Coated \\
15 & Middle-position paperboard & Uncoated \\
16 & 24 gsm middle-position paperboard & Coated \\
\hline
\end{tabular}




\section{Statistical Analysis}

The surface structure contains irregularities such as roughness, waviness, and form including position error (Costa et al. 2005; ASME B46.1-2002) and their relationships are shown in Fig 2. Roughness is defined as the finer irregularities on the surface that can be caused by either processing methods or the material. Roughness is a short and narrow spaced deviation and waviness is a long and more widely spaced deviation phenomenon (Alam at el. 2011; Reis and Saraiva 2010; Raja et al. 2002). Form and position error are also the topography components that can develop due to the shape of the sample under test and due to the insecure clamping or misalignment of the paper samples or incorrect positioning of the measuring device. Typical examples of position-error are out-of-flatness and out-of-roundness (ASME B46.1-2002).

In addition, there is also a surface deformation called cockling which develops due to a change in humidity (Gepp et al. 2009; Könnö and Stenberg 2010) and also depends on the paper fiber orientation structure (Leppänen at el. 2008). For example, during the drying process the paper fibers can shrink and this consequently creates tension among the surrounding fibers.

The prototype OnTop scans the web surface and builds line profiles. The line profiles are filtered to extract average roughness ' $\mathrm{Ra}$ ' or the rms (root mean squared) roughness 'Rq' (Alcock et al. 2010; Chinga 2006; Duparre et al. 2002).

The $\mathrm{Ra}$ and $\mathrm{Rq}$ are the functions of the profile deviations from a mean line (Stor-Pellinen et al. 1995), see Eq [1] and [2]. In general, these can be defined as the statistical data which contains an estimation of the overall surface irregularities in one variable. Fig 3 is a plot of a profile while the $\mathrm{Ra}$ and $\mathrm{Rq}$ levels are shown in order to show the differences between them. ' $\mathrm{L}$ ' is the total length scanned on the horizontal axis and ' $x$ ' is a reference mean line over which the topographical heights are measured. $\mathrm{Zx}$ is the height amplitude at each iteration over the full measurement length from $x=0$ to L-1.The surface profile height ' $Z$ ' is calculated with reference to the mean line and plotted on the vertical axis.

The widely used $\mathrm{Ra}$ and $\mathrm{Rq}$ formulas are represented in the spatial domain as;

$R a=\frac{1}{L} \sum_{x=0}^{L-1}\left(\left|Z_{x}-\bar{Z}\right|\right)$
$R q=\sqrt{\frac{1}{L} \sum_{x=0}^{L-1}\left(Z_{x}-\bar{Z}\right)^{2}}$

where $\bar{Z}$ is Mean line $=\frac{1}{L} \sum_{x=0}^{L-1} Z_{x}$

In $E q 2$ it can be noted that the height amplitudes are squared, therefore, the rms is more sensitive to the peaks and valleys in the profile. Mathematically, the relation between $\mathrm{Ra}$ and $\mathrm{Rq}$ is defined as $\mathrm{Rq} \geq \mathrm{Ra}$. How much $\mathrm{Rq}$ is larger than $\mathrm{Ra}$ depends on the scanned surface profile. For most of the samples, studied in this work, the amplitudes of $\mathrm{Rq}$ were found to be about 10-11\% higher than the Ra. All analysis results presented for the sample reels are in rms Rq.
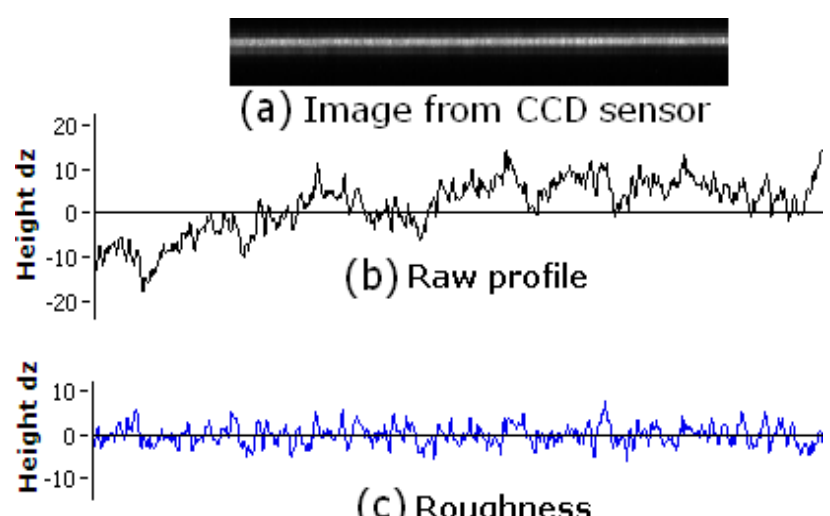

(c) Roughness

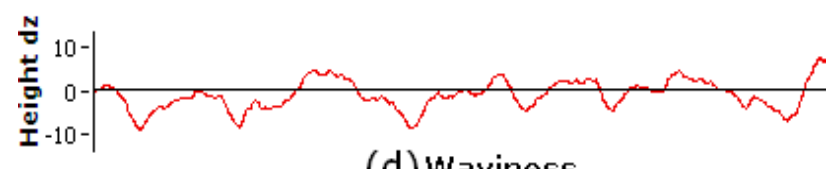

(d) Waviness

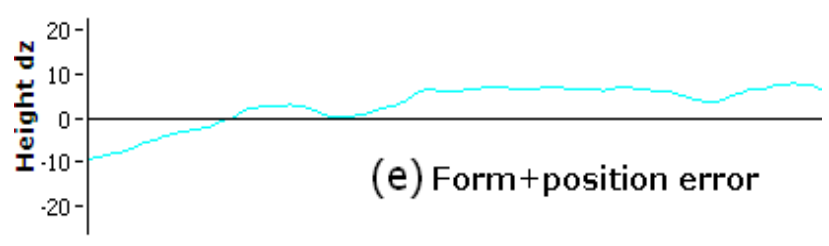

Fig 2. Shows (a) an image captured by the prototype, (b) the original profile extracted from the captured image, (c)-(e) depicts the relationship for the Roughness, Waviness and Form error components. The length of the scanned line is on the horizontal axis and the height of the profile is on the vertical axis.

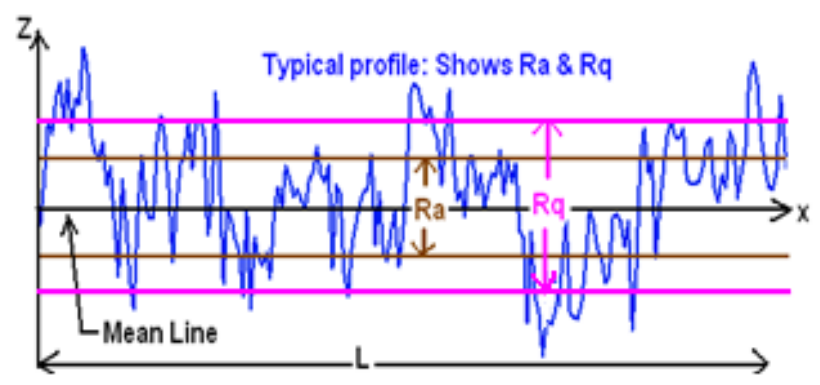

Fig 3. Average levels of roughness $\mathrm{Ra}$ and rms roughness $\mathrm{Rq}$ of a typical profile extracted from one of our samples.

\section{Results}

The performance verification of the developed prototype in a real time environment was one of the challenges as there was no such device available to make online comparisons. Therefore, a comparison between online and offline measurements was first made, and then the online surface characterization of samples, as listed in Table I, was presented. For example, comparisons were carried out for the topside versus the wireside of the newspaper reels, the coated side versus the uncoated side of the paperboard reels, and also the middle reels versus the edge reels.

\section{Online versus offline measurements}

The measurements of the 16 sample reels were obtained by i) the online device OnTop and by ii) an offline industrial profilometer, the Sture-3, and both 
measurements are plotted in Fig 4. The offline device, the Sture-3, is the third version, laboratory optical profilometer designed by MoRe Research, Sweden. It scans a paper sample point by point with a moving table mechanism and works on a laser triangulation technique. Fig 4(a) is a comparison plot for 8 paperboard reels and (b) for 8 newspaper reels. Both plots show a reasonable linear correlation between the online and offline measurements. However, some differences between the online and offline can be explained as being due to the fact that the online measurements are the average data of the whole reel, which contains a huge number of measured points, whereas the offline data are only the average of three measured points from the end of the reels, thus apparently these eight data points do not provide sufficient statistical reliability. It can be seen that the measurements for the newspaper reels have a lower correlation than for those of the paperboards reels, which could be because the online measurements were taken on the paper surface when the web was moving while the offline measurements were taken in free hanging status.

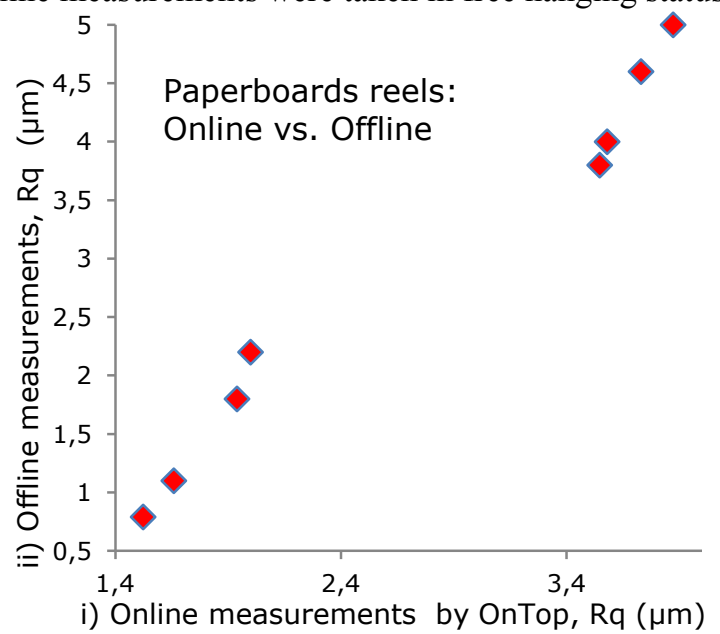

(a)

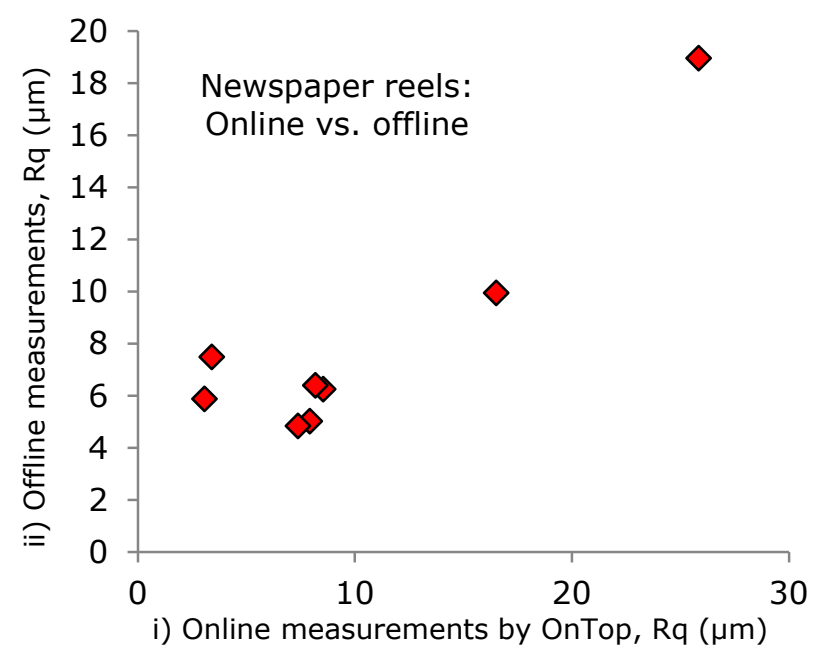

(b)

Fig 4. Comparison between i) online measurements by the OnTop and ii) offline measurements by the Industrial laboratory profilometer. Fig (a) is the comparison for 8 paperboard reels and (b) for 8 newspaper reels.

\section{Online whole reel measurements}

The pilot machine operates at $300-400 \mathrm{~m} / \mathrm{min}$ speed for the coating of the paperboard, therefore, all paperboard sample reels were measured at $400 \mathrm{~m} / \mathrm{min}$ speed. The newspapers are manufactured at higher speeds than the paperboards and as the maximum achievable speed of the pilot coating machine was $600 \mathrm{~m} / \mathrm{min}$, all the tests on newspaper reels were conducted at this speed.

The prototype was used to acquire six measurements per second, thus each measurement was obtained at every 1.11 and 1.66 meters on the paperboard reels and on the newspaper reels respectively. The measurement rate of the prototype device can be increased to be faster than six per second by optimizing the software program as there are ample possibilities.

The whole reel measurement plot, for one of the wireside newspaper reels is shown in Fig 5. On the y-axis the surface height $\mathrm{Rq}$ is given and on the $\mathrm{x}$-axis the measured length in meter, along the machine direction, is plotted. The legend of each plot also contains the average roughness $\mathrm{Rq}$ for the whole measurements. It was mentioned previously that each measurement was taken in the cross direction (CD) as illustrated in Fig 1. The measurements throughout the reel were found to be stable. The average $\mathrm{Rq}$ for the entire measurement was $3.038 \mu \mathrm{m}$ with peak to peak variations of about 2.95 to $3.15 \mu \mathrm{m}$, which is a reasonable value for this type of a wireside newspaper.

\section{The online characterization of newspaper reels}

Fig 6 shows the surface characterization of the 8 newspaper reels based on Rq roughness. Fig 6(a) is for reels of grammage of 43 and 49 gsm while Fig 6(b) is for 51 and 60 gsm reels. The roughness levels are found to be higher on the wireside as compared to the topside surface, the exception being the 43 gsm reels. This exceptional case for the $43 \mathrm{gsm}$ reels was also found in agreement with the data from the newspaper manufacturer. It was explained that the wireside could also have a smoother surface than the topside because the smoothness also depends upon the different processing steps in different machines.

In Fig 6(a) the $49 \mathrm{gsm}$ reel is detected as that having a higher surface roughness than the 43 gsm reels. Similarly in Fig 6(b) the surface roughness levels are higher for the $60 \mathrm{gsm}$ as compared to those for the $51 \mathrm{gsm}$ reels. The newspaper sample reels, on the basis of average $\mathrm{Rq}$ roughness, have been sorted out in ascending order see Table II.

Table II. Roughness based classification of the Newspaper samples sorted out in ascending order.

\begin{tabular}{llll}
\hline Reel Nr. & Description & Surface & Rq $(\boldsymbol{\mu m})$ \\
\hline 5 & 51 gsm, Newspaper & Topside & 3.032 \\
1 & 43 gsm, Newspaper & Wireside & 3.038 \\
6 & 51 gsm, Newspaper & Wireside & 3.172 \\
2 & 43 gsm, Newspaper & Topside & 3.231 \\
7 & 60 gsm, Newspaper & Topside & 3.345 \\
8 & 60 gsm, Newspaper & Wireside & 3.506 \\
3 & 49 gsm, Newspaper & Topside & 4.523 \\
4 & 49 gsm, Newspaper & Wireside & 5.480 \\
\hline
\end{tabular}




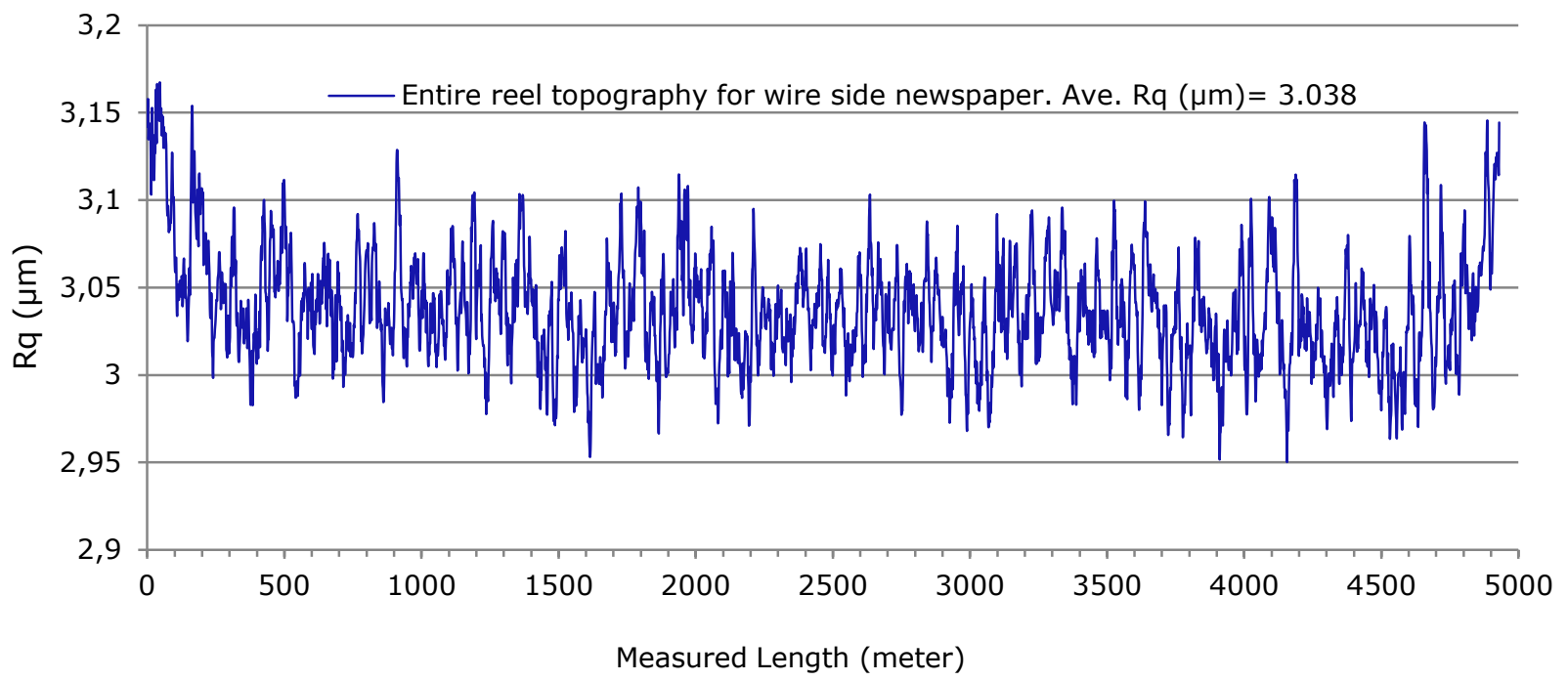

Fig 5. Example of an online roughness measurement for the whole reel. Total length measured about 5,000 meters, average Rq $=3.038 \mu \mathrm{m}$ with peak to peak variations of about 2.95 to $3.15 \mu \mathrm{m}$ which is a reasonable value for such kind of a wireside newspaper.

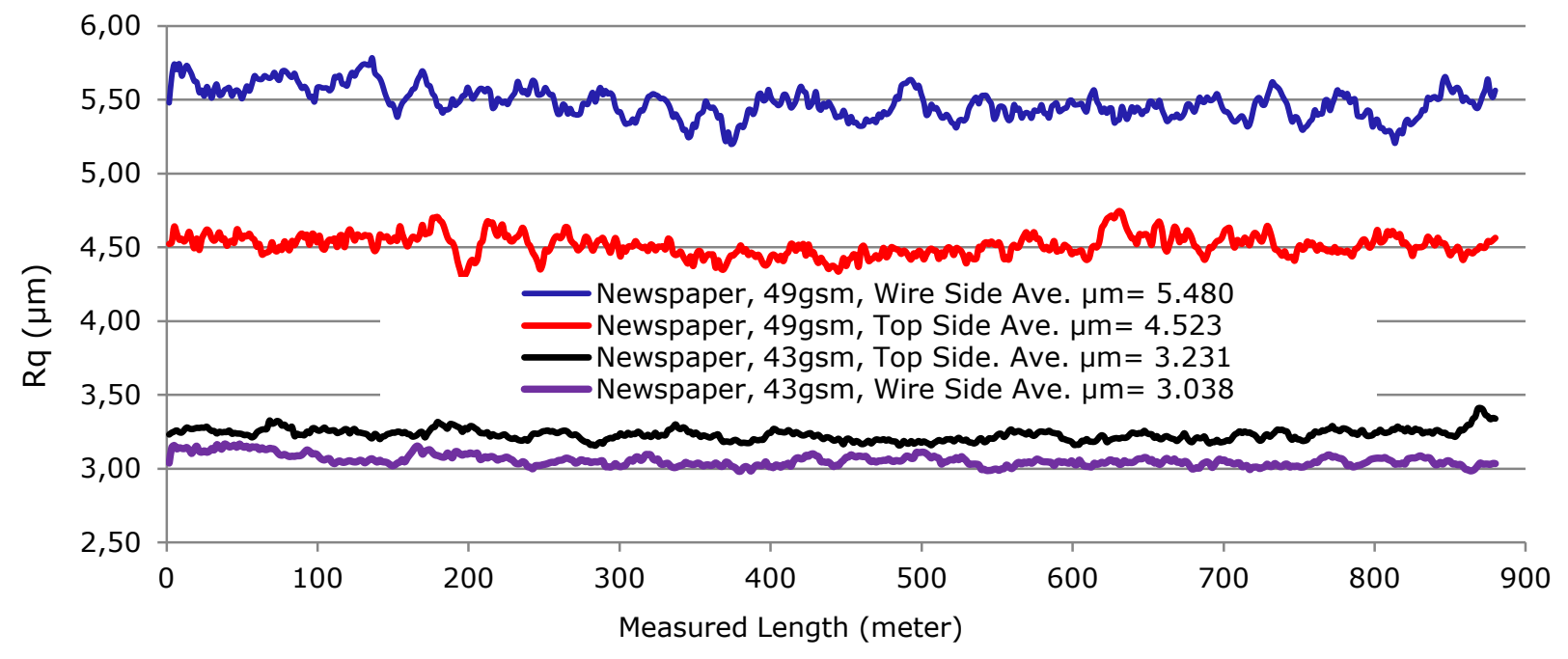

(a)

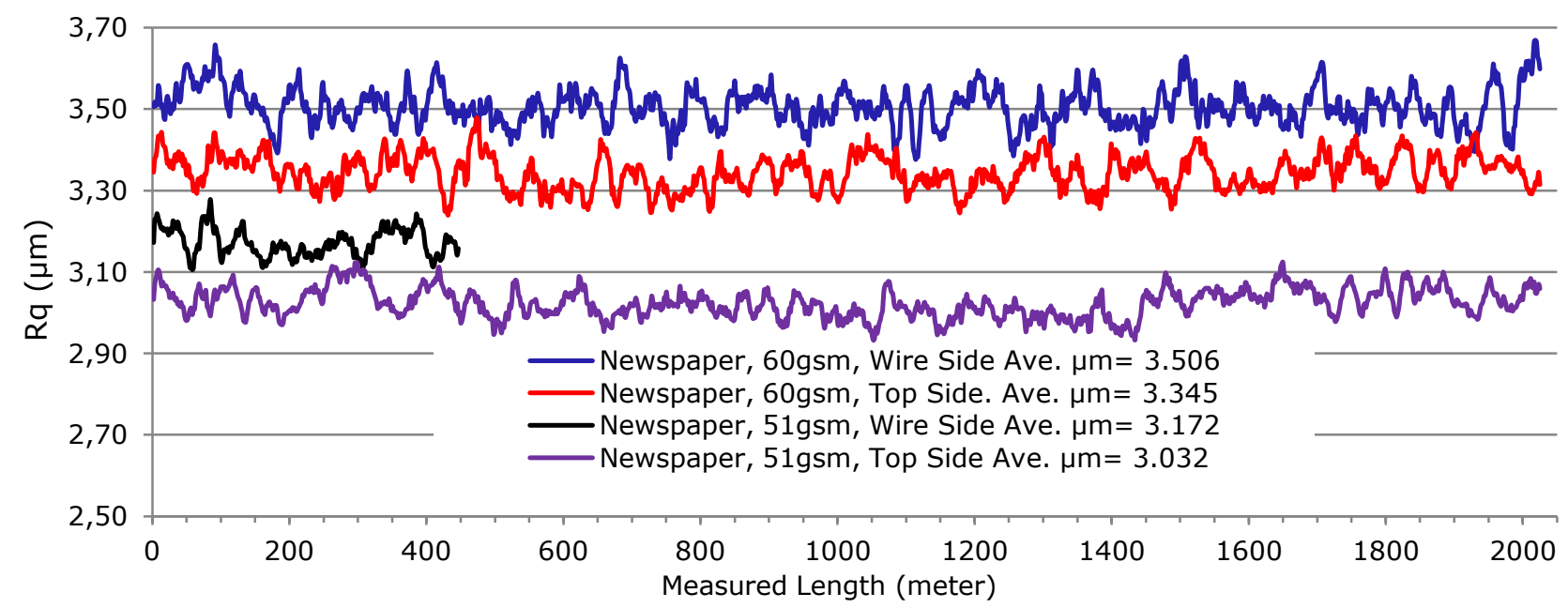

(b)

Fig 6. Online roughness comparison among the newspaper sample reels of grammage 43, 49, 51 and $60 \mathrm{gsm}$. 


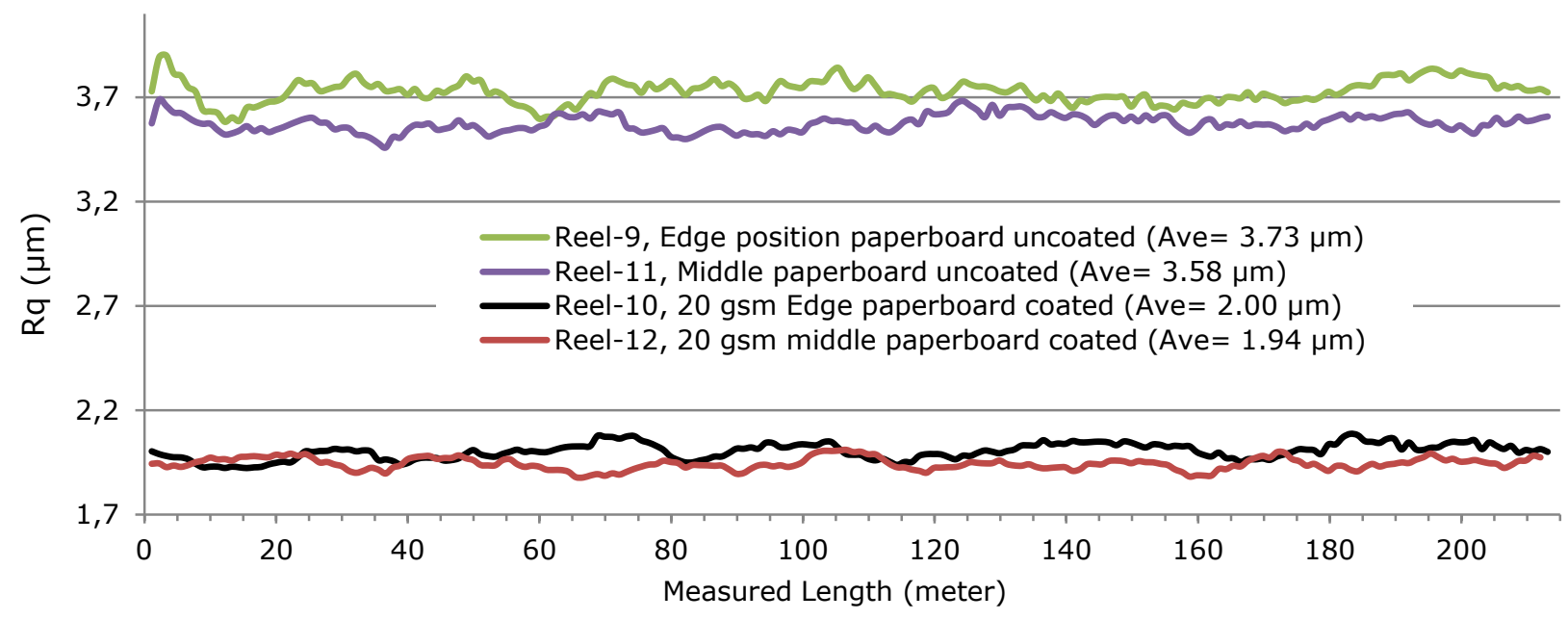

(a)

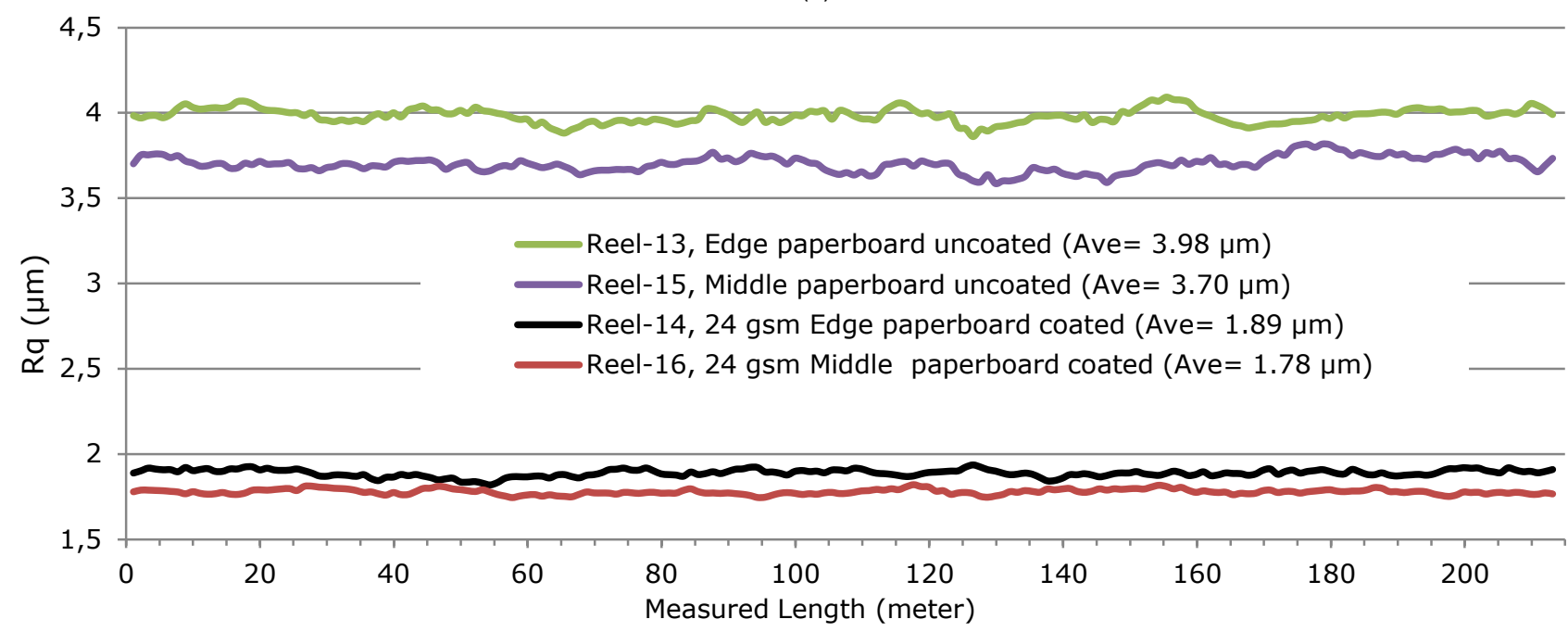

(b)

Fig 7. Online roughness comparison for the paperboard reels. Both (a) and (b) have a total measurement length of 213 meters.

Table III. Roughness based classification of the paperboard samples sorted out in ascending orders.

\begin{tabular}{llll}
\hline $\begin{array}{l}\text { Reel } \\
\text { No. }\end{array}$ & Description & Surface & $\begin{array}{l}\text { Rq } \\
(\boldsymbol{\mu m})\end{array}$ \\
\hline 16 & 24 gsm Middle paperboard & Coated & 1.78 \\
14 & 24 gsm Edge paperboard & Coated & 1.89 \\
12 & 20 gsm middle paperboard & Coated & 1.94 \\
10 & 20 gsm Edge paperboard & Coated & 2.00 \\
11 & Middle paperboard & Uncoated & 3.58 \\
15 & Middle paperboard & Uncoated & 3.70 \\
9 & Edge paperboard & Uncoated & 3.73 \\
13 & Edge paperboard & Uncoated & 3.98 \\
\hline
\end{tabular}

\section{The online characterization of paperboard reels}

In a similar manner to that for the newspaper reels, the online surface characterization results, of 8 paperboard reels are plotted in Fig 7. In both Fig 7(a) and (b) the roughness amplitudes were found higher for the uncoated sides compared to the coated sides, which is an obvious result.
Figs $7(a)$ and (b) contain the important results relating to the edge reels and the middle reels. It is already known that roughness differences between the edge position and middle position reels are very low and that the roughness on the edge reel is expected to be slightly higher because of the shrinkages of fibres in the processing steps. The same is evident in the plots of the edge and the middle reels in figures (a) and (b) both for the coated and uncoated surfaces of the paperboard.

One more important result can be observed in these plots, relating to the roughness difference between $20 \mathrm{gsm}$ and 24 gsm coat weight paperboards. The coated surfaces of Reels 14 and 16 were expected to be smoother than those for Reels 10 and 12 and the same was detected in their respective online plots. Table III classifies all the 8 paperboard sample reels based on their average roughness, starting from the smoothest surface.

\section{Discussion and conclusions}

The technique and the processing method adopted in the design of the prototype allowed the whole reel measurement to be made, meter by meter, on the paper web, moving at high velocities in real time. It is definitely 
possible to increase the current prototype measurement rate of six per second by optimizing the software and if the only interest is in measuring the average roughness in a single variable of $\mathrm{Ra}$ or $\mathrm{Rq}$. The online results presented have achieved the micro level roughness measurements and have shown that the prototype method can differentiate between surfaces of very similar roughness, making the method useful for the paper and paperboard industries. The tests, conducted to compare online and the offline measurements, give hints as to the accuracy of the OnTop prototype method.

The real time surface profile data offer the potential to extract and measure the surface irregularity components such as cockling and waviness in addition to roughness.

The developed prototype and the experimental results have provided proof that the exploitation of simple and economical laser triangulation technique can not only be a valuable application for online surface topography measurements in both the paper and paperboard industries, but also for other related industrial applications.

\section{Acknowledgements}

Knowledge Foundation, Sweden is gratefully acknowledged for its financial support. Thanks to Krister Alden of Mid Sweden University, Sundsvall Sweden for his technical help in accomplishing this prototype. Thanks must also be given to Professor Bengt Oelmann for his great support and inspiration and for providing the motivation to encourage the researchers in the department.

\section{Literature}

Aguilar, J. R., Arenas J.P. and Salinas, R. (2009): Friction noise technique for the measurement of surface roughness of papers, Applied Acoustics, 70(9), 1235-1240.

Alam, A., Thim, J., Manuilskiy, A., O'Nils, M., Westerlind., C., Lindgren, J. and Lidén, J. (2011): Investigation of the surface topographical differences between the Cross Direction and the Machine Direction for newspaper and paperboard. Nord. Pulp Paper Res. J. 26(4), 468-475.

Alam, A., Thim, J., O'Nils, M., Manuilskiy, A., Lindgren, J. and Lidén, J. (2012): Online surface characterization of paper and paperboards in a wide-range of the spatial wavelength spectrum, Appl. Surf. Sci., http://dx.doi.org/10.1016/j.apsusc.2012.04.136, in press

Alcock, S.G., Ludbrook, G.D., Owen, T. and Dockree, R. (2010): Using the power spectral density method to characterise the surface topography of optical surfaces, Proceedings of SPIE -The International Society for Optical Engineering, 7801(780108), Advances in Metrology for X-Ray and EUV Optics III; San Diego, CA.

Åslund, P., Johansson, P.-A. and Blohm, E. (2004): Photometric method for dynamic measurements of paper roughening after a moistening printing nip , Nord. Pulp Paper Res. J., 19(4),460-465.

ASME B46.1-2002 (2002): Surface Texture, Surface Roughness, Waviness and Lay. An American National Standard, the American Society of Mechanical Engineers.
Barros, G.G. and Johansson, P. -Å (2005): The OptiTopo technique for fast assessment of paper topography -Limitatios, applications and improvements, Journal of Imaging Science and Technology, 49(2), (170-178).

Bilstein, W., Enderle, W., Moreas, G., Oppermann, D., Routschek, T. and Velde F.V.D. (2007): Two Systems for OnLine Oilfilm and Surface Roughness Measurement for Strip Steel.Production, An Int. Journal of Metallurgy, 104, 348-353.

Cheng, V.S., Hao, L.J., Chen, X.Z., Zhang, S. and Chen, Y.Z. (2007): Laser vision system based on synchronized scanning method Lecture Notes in Control and Information Sciences2007 362 83-89

Chinga, G. (2006): A quadtree decomposition approach for surface assessment, Pattern Analysis and Applications, 9(1), 94-101.

Costa, R., Angélico, D., Reis, M.S., Ataíde, J.M. and Saraiva, P.M. (2005): Paper superficial waviness: Conception and implementation of an industrial statistical measurement system Analytica Chimica Acta 544 (1-2), (135-142).

Duparre, A., Ferre-Borrull J., Gliech, S., Notni, G., Steinert, J. and Bennett, J.M. (2002): Surface Characterization Techniques for Determining the Root-Mean-Square roughness and Power Spectral Denstities of Optical Components, OSA Journal Applied Optics, 41(1), (154-171).

Gepp, S., Örtegren, J., Hägglund, J.-E. and Alfthan, E. (2009): Measuring cockling on-line in high speed inkjet printing. Int. Conf. on Digital Printing Tech. 521-523.

Goic, G.L., Favrelière, H., Samper, S. and Formosa, F. (2011) Multi Scale Modal Decomposition of Primary Form, Waviness and Roughness of Surfaces. Scanning 33, 1-10.

Gunnar Engstrom, Veronique Morin (1994): Quantitative description of the increase in surface roughness of the base paper during coating, Nord. Pulp Paper Res. J., 9(2), 106-110.

Hansson, P. and Johansson, P -A. (1999): New method for the simultaneous measurement of surface topography and ink distribution on prints, Nord. Pulp Paper Res. J. 14(4), 315-319.

Hladnik, A. and Lazar, M. (2011): Paper and board surface roughness characterization using laser profilometry and gray level cooccurrence matrix, Nord. Pulp Paper Res. J. 26(1), 99105.

Könnö, J. and Stenberg, R. (2010): A Finite element analysis of composite plates with an application to the paper cockling problem Finite Elements in Analysis and Design 46 265-272.

Kuparinen, T., Rodionov, O., Toivanen, P., Mielikainen, J., Bochko, V., Korkalainen, A., Parviainen, J., Vartiainen, E. (2005): Fractal Dimension Analysis and Statistical Processing of Paper Surface Images Towards Surface Roughness Measurement. SCIA Lecture Notes in Computer Science 3540, 1218-1227

Leppänen, T., Erkkilä, A.-L. and Hämäläinen, J. (2008): Effect of fiber orientation structure on simulated cockling of paper. J. Pulp Paper Sci. 34 (4), 226-233.

Litvinov, V. and Farnood, R (2006) Modeling thickness and roughness reduction of paper in calendering. Nord. Pulp Paper Res. J. 21 (3), 365-371

Ma, J. (2005): Towards artifact-free characterization of surface topography using complex wavelets and total variation minimization Applied Mathematics and Computation 170 10141030 
Ostadi, H., Jiang, K. and Hukins D.W.L. (2010): A comparison of surface roughness analysis methods applied to urinary catheters Precision Engineering 34 798-801

Pierre, V., Jean-Francis, B., Christophe, M., Anne, B., and Bernard, P. (2008): Statistical analysis of paper surface microstructure: A multi-scale approach, Applied Surface Science, 254(22), 7431-7437.

Pino, A.O., Pladellorens, J. and Colom, J.F. (2010): Method of measure of roughness of paper based in the analysis of the texture of speckle pattern Proceedings of SPIE - The Int. Society for Optical Engineering Rosario Argentina 7387, art. no. $73871 \mathrm{~W}$

Raja, J.B., Muralikrishnan, B. and Fu, S. (2002): Recent advances in separation of roughness, waviness and form Journal of the International Societies for Precision Engineering and Nanotechnology 20 222-235.

Rättö, P. (2005): The influence of surface roughness on the compressive behaviour of paper, Nord. Pulp Paper Res. J., 20(3), 304-307.

Reis, M.S. and Saraiva, P.M. (2010): Analysis and Classification of the Paper Surface, Ind. Eng. Chem. Res. 49 2493-2502.

Ren, J., Gao, X.-R., Peng, J.-P. and Guo, J.-Q. (2010): Research on 2D laser distance sensor, Proceedings of SPIE The Int. Society for Optical Engineering 7544, art. no. 75444Q.

Singh, S.P. (2008): A comparison of different methods of paper surface smoothness evaluation, BioResources, 3 503-516.

Rodríguez-Jiménez, S., Álvarez, I., García, R. and Marina, J. (2010): Analysis of Block Matching Algorithms for the Application of Image Mosaicing to Online Surface Inspection of Steel Products IEEE Int. Conf. on Imaging Systems and Techniques, IST 2010 - Proceeding 5548491 214-219.
Samyn, P., Van Erps, J., Thienpont, H. and Schoukens, G. (2011): Paper coatings with multi-scale roughness evaluated at different sampling sizes. Applied Surface Science 257 (13), 5613-5625

Schwaiger, E., Kandelbauer, A. and Teischinger, A. (2009) Practicalities and limitations of measuring techniques for paper properties that affect flexographic printability - A review. Nord.

Pulp Paper Res. J. 24 (3), 351-362

Stor-Pellinen, J. and Luukkala M. (1995): Paper roughness measurement using airborne ultrasound Sensors and Actuators: A. Physical 49 37-40.

Tay, C.J. and Quan, C. (2003): A parametric study on surface roughness evaluation of semi-conductor wafers by laser scattering Optik (Jena) Int. Journal for Light and Electron Optics 114 01-06.

Thim, J., O'Nils, M., Manuilskiy, A. and Thörnberg, B. (2009): Simulating the Impact of Topographical Microstructures on Triangulation Measurement Setups Using MATLAB. Matlabe User Conf. Nordic 2008 Stockholm.

Vernhes, P., Bloch, J.-F., Mercier, C., Blayo, A. and Pineaux, B. (2008): Statistical analysis of paper surface microstructure: A multi-scale approach, Applied Surface Science, 254(22), 7431-7437.

Wu, G., Kwak, H., Jnag, S., Xu, K. and Xu, J. (2008): Design of Online Surface Inspection System of Hot Rolled Strips. Proc. IEEE Int. Conf. on Automation and Logistics, ICAL 2008 Qingdao 4636548 2291-2295.

Manuscript received November 22, 2011 Accepted February 16, 2012 